\title{
Lusíada
}

Repositório das Universidades Lusíada

\section{Universidades Lusíada}

\author{
Moreira, Paulo \\ Inman, Richard A. \\ Cunha, Diana \\ Cardoso, Nuno
}

\section{Functions of identity in the context of being a student: Development and validation of the Functions of Student Identity Scale}

http://hdl.handle.net/11067/5720

\section{Metadados}

Data de Publicação

Resumo

Editor

Palavras Chave

Tipo

Revisão de Pares

Coleções

2019

A promising approach to the understanding of identity is the identity functions framework. However, its developmental specificities associated with adolescence remain unexplored. The aim of this study was to develop and test a new measure of the functions of identity as they relate to being a student. Consistent with the theoretical framework, an exploratory analysis with a subsample of high school students revealed five identity functions. A confirmatory analysis with a second subsample fo...

Taylor \& Francis Online

Identity, Identify functions, Functions of Student Identity Scale (FoSIS), Psychometrics, Bifactor

article

yes

[ILID-CIPD] Artigos

Esta página foi gerada automaticamente em 2023-04-26T14:19:50Z com informação proveniente do Repositório 


\title{
Functions of identity in the context of being a student: Development
}

\author{
and validation of the Functions of Student Identity Scale
}

\author{
Paulo A. S Moreira ${ }^{\mathrm{a}, \mathrm{b}}$ \\ Richard A. Inman ${ }^{\mathrm{a}, \mathrm{b}}$ \\ Diana Cunha ${ }^{\mathrm{a}, \mathrm{b}}$ \\ Nuno Cardoso ${ }^{\mathrm{b}}$
}

${ }^{a}$ Instituto de Psicologia e Ciências da Educação, Universidade Lusíada Norte (Porto), Porto, Portugal

${ }^{b}$ Centro de Investigação em Psicologia para o Devenvolvimento [The Psychology of Positive Development Research Center] (CIPD), Porto, Portugal

Note. This document is the authors' version of the final accepted manuscript, published in 2019 by Identity: An International Journal of Theory and Research doi: 10.1080/15283488.2019.1566069

https://www.tandfonline.com/doi/full/10.1080/15283488.2019.1566069

Funding: This research was supported by grants from the Portuguese Foundation for Science and Technology (FCT) (PTDC/MHC-CED/2224/2014; and CIPD-BI-UID/PSI/04375/2016) and by the Minerva Foundation - Ensino, Cultura e Investigação Científica (the founding organization of the Lusíada Universities).

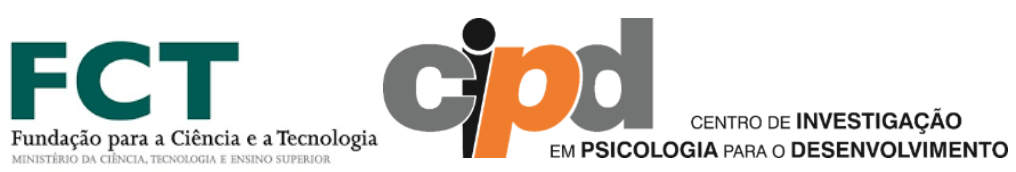




\begin{abstract}
A promising approach to the understanding of identity is the identity functions framework. However, its developmental specificities associated with adolescence remain unexplored. The aim of this study was to develop and test a new measure of the functions of identity as they relate to being a student. Consistent with the theoretical framework, an exploratory analysis with a subsample of high school students revealed five identity functions. A confirmatory analysis with a second subsample found that a higher-order model incorporating these five subscales demonstrated good fit to the data. A bifactor model and statistical indices indicated that it is appropriate to interpret a total student identity score using this instrument. The five subscales, and total scale, demonstrated good convergent validity with a measure of academic behavioral change. These preliminary results suggest that this new instrument presents good psychometric properties and that it is a suitable assessment instrument for the measurement of students' processes and outcomes. For example, its associations with academic performance stages of changes suggest that this instrument will be useful for identifying students at risk for poor academic trajectories.
\end{abstract}

Keywords: identity, identify functions; Functions of Student Identity Scale (FoSIS), psychometrics, bifactor; 


\section{Introduction}

According to Erikson's influential and classic theory of psychosocial development (1968) human social development occurs through the progression of eight stages. Starting at infancy and ending in late adulthood, these eight stages each present unique challenges that the developing individual must master in order to progress. The primary challenge attributed to the period of social development during adolescence (13 to 19 years), a result of the confluence of physical and cognitive development and social expectations (Marcia, 1980), is the discovery and development of one's own identity: The answer to the question "Who am I?".

Since Erikson's original writings, the theory of identity has been expanded and extended empirically by multiple authors, perhaps most notably by Marcia (1966, 1980). Marcia described four types of identity status, each varying in their degree of identity exploration and commitment: Diffused, foreclosed, moratorium, and achieved. At the two extremes, identity diffusion describes low commitment to a set of ideals and low exploration of one's self, while identity achievement describes a state of high commitment to values and ideals after high exploration. Identity moratorium describes an active exploration of alternatives but prior to making a commitment. Conversely, identity foreclosure describes commitment without prior exploration. The achieved identity status is typically considered to describe the most mature formation of identity, and this is supported by evidence that associates it with balanced thinking and the development of mature relationships (Berzonsky, 2004; Schwartz, 2001; Schwartz et al., 2011).

Within his theory, Erikson referred to different angles from which ego identity can be observed: the personal and the social (Schwartz, 2001). Others have since argued for a clear distinction between decontextualized personal identities (traits and 
characteristics such as being a nice person) and context-specific social identities (e.g. being a student; Oyserman, 2009; Oyserman et al., 2017). These dimensions of identity can be considered as lying at opposing ends of a continuum (Howard, 2000) but with strong interrelations (Deaux, 1993). Based on this perspective, identity expresses differently across personal and social domains (Grotevant, 1993) and context influences which identities are salient to the individual (Oyserman, 2007). Moreover, the identities that become salient across contexts influence behaviour and meaning-making (Oyserman et al., 2017).

In accordance with these theoretical proposals, researchers have developed instruments that allow for the assessment of identity status as it relates to specific contexts, such as being a student (e.g. the Academic Identity Measure; Was \& Isaacson, 2008). Such measures capture the four identity statuses described by Marcia (1966): "Sometimes I think the reason I'm in college is I have nothing better to do" (Diffused), "I never decide on my own about college" (Foreclosed), "My priorities in school are in transition" (Moratorium), and "I've considered a number of college majors and have decided which one is best for me" (Achieved) (Was \& Isaacson, 2008). Empirical studies have indicated that an achieved academic identity status is associated with better academic performance (Hejazi, Lavansani, Amani, \& Was, 2012; Ireri, Wawire, Mugambi, \& Mwangi, 2015; Was \& Isaacson, 2008), less self-handicapping behavior such as procrastination (Chorba, Was, \& Isaacson, 2012), an approach (rather than avoidance) goal orientation (Hejazi et al., 2012), more intention to continue with education long-term (Roeser et al., 2008), and the ability to work well under stress (Was, Al-Harthy, Stack-Oden, \& Isaacson, 2009). Such findings highlight that it is practically relevant to understand the expression of identity in specific contexts as a likely way to promote positive behaviour and adaptive context-specific outcomes. 


\section{The Functions of Identity}

According to Adams and Marshall (1996), identity serves the self-regulatory functions of focusing attention, filtering and processing information, and managing and directing behaviour selection. From this perspective, these functions can differentiate identity statuses into those that are active and self-constructed (achieved and moratorium statuses), and those that are passive (diffused and foreclosed statuses). More specifically, Adams and Marshall (1996) described five common functions of identity. We list these functions below with examples of empirical studies that imply functions differ for identities with active (particularly achieved) statuses compared to passive statuses.

(1) Providing the structure for understanding who one is (Structure). If adolescents have a solid structure for understanding themselves then this, according to theory, tends to manifest as high self-esteem and self-acceptance (Adams \& Ethier, 1999). In line with this, identity status has been shown to be associated with self-esteem in students, with the achieved status related to higher self-esteem (Komarraju \& Dial, 2014; Ryeng, Kroger, \& Martinussen, 2013).

\section{(2) Providing meaning and direction through commitments, values and goals}

(Objectives). Evidence indicates that an achieved identity status is positively associated with the adoption of adaptive achievement goals in the context of school (cognitive representations of competence that help guide behaviour), and particularly those focused on investing effort as a means to develop competence and task mastery (Hejazi et al., 2012). Similarly, the achieved identity status has been shown to be associated with goal-directed behavior and self-motivation (Blustein \& Palladino, 1991).

\section{(3) Providing a sense of personal control and free will (Personal Control).}

Adolescents with an achieved identity have been shown to have lower levels of external 
locus of control and higher levels of internal locus of control (Abraham, 1983; Lillevoll, Kroger, \& Martinussen, 2013). Similarly, achieved identity has been linked to selfefficacy (Serafini \& Maitland, 2013), which implies an internal attribution of success.

(4) Striving for consistency, coherence, and harmony between values, beliefs, and commitments (Harmony). This function implies that individuals with an active identity status will be better adjusted, and indeed studies have shown that students with a stronger identity have better academic adjustment (Carlson, 1986). Furthermore, studies also indicate that that individuals with an achieved identity status have a more developed psychosocial maturity (Adams, Berzonsky, \& Keating, 2006).

(5) Enabling the recognition of potential through a sense of future, possibilities and alternative choices (Future). This function implies that students with an achieved identity status will be more likely to recognize potential in future possibilities, and thus more likely to invest in academic achievement and future planning. Consistent with this, students with achieved identity statuses have both better academic performances, and show more desire to pursue education long-term (Roeser et al., 2008).

\section{The Functions of Identity Scale (FIS)}

Given the empirical support for the five functions of identity, Serafini and Adams ( 2002) developed the Functions of Identity Scale. Items in this scale were designed to represent the conceptual space occupied by the five functions described by Adams and Marshall (1996). Example items include: "I am certain that I know myself" (Structure); "I tend to set goals and then work towards making them happen" (Goals); "Much of who I am seems to be based on compliance to my parent(s) wishes" (Control); "My values and beliefs are an accurate reflection of who I am" (Harmony); and "I am undecided about where I will be in the future" (Future). It is important to note here that the active identity category described by Adams and Marshall (1996) corresponds 
closely to Erikson's (1968) optimal identity. Moreover, the five self-regulatory functions of identity result when adolescents are actively engaged in identity development. When one's identity has an achieved or moratorium status it follows that it will more completely serve the functions of providing a structure for understanding oneself, providing meaning and direction via goals and values, providing a sense of personal control, providing consistency between values and beliefs, and providing the ability to recognize potential. Conversely, an identity with a passive status will less adequately serve these functions. In other words, an individual's total score with the FIS is an indication of the degree of active self-construction and, by extension, optimal identity.

Several studies using exploratory (Serafini \& Adams, 2002, Study 1) and confirmatory (Crocetti, Sica, Schwartz, Serafini, \& Meeus, 2010; Demir, 2011, Serafini \& Maitland, 2013) factor analyses have shown English, Italian, and Turkish versions of this instrument conform to a correlated five-factor structure, corresponding to the five functions of identity, although note that only one study tested a higher-order model(Serafini \& Maitland, 2013) . The five subscales of the FIS have been shown to have good internal consistency $(.69<\alpha>.89$; Serafini \& Adams, 2002, Study 1). This instrument also has acceptable test-retest reliability and convergent validity. Specifically, the five functions were positively correlated with Berzonsky's (1989) informational and normative identity styles, and negatively correlated with the diffuseavoidance identity style(Crocetti, Sica, Schwartz, Serafini, \& Meeus, 2013).).

\section{The Functions of Identity in Students: The Need for a New Scale}

Although the FIS has been tested and validated in numerous studies it is clear that its items, although founded on the Eriksonian (1968) ideas of development and achievement of an optimal personal or ego identity, do not align well with the idea that 
context shapes and constructs one's in-the-moment identity orientation (Oyserman, 2007). Indeed, it has been argued that empirical evidence (Goossens, 2001; Pastorino, Dunham, Kidwell, Bacho, \& Lamborn, 1997; Rogow, Marcia, \& Slugoski, 1983) indicates that adolescent identity should not be considered as a global construct (global identity statuses provide a less detailed account of the complexity of identity development), with the implication that domain-specific instruments should be used whenever possible (Goossens, 2001). This is particularly the case if the instruments are being used to test associations between identity and a domain-specific variables such as student engagement in school or academic performance.

Moreover, although context-specific identity status in relation to being a student can be assessed using measures such as the Academic Identity Measure (Was \& Isaacson, 2008), there are currently no instruments that allow for a direct measure of the self-regulatory functions of identity as they relate to being a student. It is therefore important to develop and test such an instrument. Not only is education a highly important social institution for guiding individuals from childhood to adulthood, but identity and its expression in the domain of being a student during this transitional period is linked to the developmental trajectories taken via its influence on behaviour.

To explain this, we refer to Terry, Hogg and White (1999), who postulated in their consideration of the Theory of Planned Behaviour (Ajzen, 1985, 1987) that identity should theoretically precede behavioural change. This, they proposed, occurs via an influence on behavioural intentions, as contextualised identities define roleappropriate behavioural expectations. Moreover, people prefer to behave in identity congruent ways (Oyserman et al., 2017). In short, what this implies is that individuals who identify as being a student are more likely to have the intention to engage in role- 
congruent student behaviours in order to reach desired future identities (to be whom they want to be).

These theoretical links are generally supported (Webb \& Sheeran, 2006), and studies have supported this theory in the context of school. Biddle, Bank and Slavings (1987), for example, found that having a 'continuing-student' identity significantly predicted students' intentions to continue education, which itself predicted school continuation. More generally, other empirical evidence indicates that student identity and its correlates, such as personality, academic involvement, and motivation, are associated with academic performance (Moreira, Dias, Vaz, \& Vaz, 2013; Noftle \& Robins, 2007; Poropat, 2009; Roeser et al., 2008).

It is thus clear that examining the construct of student identity, via the development of a new measurement scale of the functions that result from identity development, will be valuable for developing an understanding of how the self expresses in the role of being a student. Furthermore, this endeavour will be crucial for informing interventions and policies aimed at promoting positive academic trajectories. Having a valid assessment instrument of student identity is vital because it is likely to help identify students at risk for disengagement/ school dropout. This identification process will then help target interventions and to promote better career guidance for those who do not identify as students.

Based on this rationale, our objective is to present a new measure of student identity for use with adolescents (the Functions of Student Identity Scale; FoSIS) based on the functions of identity perspective described by Adams and Marshall (1996), and then to conduct the first empirical tests of its validity. Furthermore, because identity is theorised to influence behaviour change by shaping behavioral intentions it follows that students scoring high on our measure should also do so for an indicator of active 
behavioral change. We shall use the Academic Stages of Change Inventory (Moreira, Moreira, Cunha, \& Inman, 2018), which measures behavioral change in terms of five stages moving from an absence of motivation to change to contemplation, preparation, active implementation of change, and finally maintenance of changed behaviors.

\section{Method}

\section{Participants}

A total of 588 Portuguese high school students from four schools in the north of Portugal were recruited for the present study. Students represented the $10^{\text {th }}(n=218)$, $11^{\text {th }}(n=168)$ and $12^{\text {th }}$ grades $(n=202)$, and therefore had a mean age of 16.7 years $(S D$ $=1.5)$. In terms of gender distribution, $41.7 \%$ of the sample were male and $58.3 \%$ were female. For the sake of analyses, the overall sample was randomly divided into two separate sub-samples after cases with missing values were excluded listwise (deemed appropriate because missing values were missing completely at random, MCAR). Sample $1(n=267)$ was used for exploratory factor analysis. Sample $2(n=272)$ was used for confirmatory factor analysis.

Sample 1 comprised 113 males and 154 females, with a roughly equal distribution across the $10^{\text {th }}(94), 11^{\text {th }}(76)$ and $12^{\text {th }}(97)$ grades. The mean age of Sample 1 was $16.7(S D=1.5)$. Sample 2 comprised 112 males and 160 females. As with Sample 1 , students were roughly evenly distributed across the $10^{\text {th }}(103) 11^{\text {th }}(80)$ and $12^{\text {th }}(89)$ grades. The mean age of participants in Sample 2 was $16.5(S D=1.5)$.

\section{Measures}

Participants completed two questionnaires to assess student identity and academic performance stage of change. Both instruments were developed in Portugal 
and are written in Portuguese, but we offer English translations of example items for the purpose of this manuscript.

Functions of Student Identity Scale (FoSIS). The FoSIS is a self-report measure of student identity. An original pool of 27 items was created by Moreira and Cardoso (2010) to reflect the five functions defined by Adams and Marshall (1996). Items reflected: consistency and coherence between values, beliefs, and commitments concerning studentship (Harmony; "I feel good about being a student"); meaning and direction through commitments, values, and goals (Objectives; "I strive to achieve the goals I have as a student"); structure for understanding who one is (Structure; "I know what my main qualities are as a student"); ability to recognize potential in the form of future possibilities and alternative choices (Future; "I have a clear idea of what my future will be as a student"); and perceptions of personal control and free will (Personal Control; "What I do as a student results from my decisions"). All items are scored on a 5-point Likert scale from 1 (Totally disagree) to 5 (Totally agree). High scores for each subscale indicate that student identity is performing this function while low scores indicate that student identity is performing this function minimally. Higher overall FoSIS scores were therefore taken as an indication of more active self-construction. The psychometric properties of these original 27 items were not empirically tested by Moreira and Cardoso (2010).

As part of a refinement process that has occurred since the creation of the original pool of items, a panel of academics who are experts in educational psychology reviewed the pool of items. These experts rated items on their relevance to the construct of student identity and representatives of their respective factor. Experts were also able to offer feedback and suggested modifications to items where necessary. We also conducted a preliminary exploratory factor analysis with a small sample different to that 
reported in the present study. This revealed a number of items that did not appear to load onto their proposed factors. This combined process resulted in a final pool of 19 items.

Academic Performance Stages of Change (APSCI). The APSCI (Moreira et al., 2018) is a self-report measure of student motivation to improve academic performance. The instrument consists of 14 items, all scored on a five-point Likert-type scale. Consistent with the theory of stages of change, Moreira et al (2018) showed through exploratory and confirmatory factor analyses that these items correspond to five distinct stages. These stages, moving from least to most motivated, are: Precontemplation (3-items, e.g. "The fact that my grades aren't good doesn't worry me", alpha $=.72)$; Contemplation (2-items, e.g. "I really need to improve my grades", alpha =.66); Preparation (3-items, e.g. "I would like to have help to fulfil what I have planned in order to improve my grades", alpha = .79); Action (3-items, e.g. "I'm trying hard to improve my grades", alpha = .65); and Maintenance (3-items, e.g. "There are days when I do what I can to improve my grades, but there are other days when I can 't', alpha $=.57)$. As well demonstrating that these five scales had generally good internal consistency, Moreira et al. (2018) also showed that the five-factor model was invariant across gender and school grades: the construct of stages of change was equivalent for boys and girls, and at different ages.

\section{Procedure}

Ethical approval was obtained from the ethics committee at the Universidade de Lusíada, Porto, Portugal. A number of schools in the north of Portugal were approached using a convenience sampling technique and in total, four schools agreed to participate in the study. Prior to data collection, all students enrolled in our target grades $\left(10^{\text {th }}-\right.$ $\left.12^{\text {th }}\right)$ in these schools were given informed consent forms with which to obtain consent 
from their parents or legal guardians. Any students over the age of 18 were allowed to give their own consent. Students who returned signed consent forms were then able to complete the questionnaires in groups while being supervised by a member of the research team.

\section{Statistical Analysis}

Exploratory factor analysis. We used Sample 1 for the first series of exploratory analyses. Prior to conducting EFA, the Kaiser-Meyer-Olkin (KMO) measure of sampling adequacy was calculated and, based on the guidelines proposed by Hutcheson \& Sofroniou (1999), the overall adequacy of the variables for factor analysis was deemed to be 'meritorious' $(\mathrm{KMO}=.80)$. KMO values for individual variables were all above .67. To determine a suitable number of factors to extract we conducted Parallel Analysis, which contrasts eigenvalues obtained from the correlation matrix of scale items with those from a random dataset. We then conducted an exploratory factor analysis, based on polychoric correlations, using a minimal residual method and an oblique Oblimin rotation to force the extraction of the number of factors identified by Parallel Analysis.

Confirmatory factor analysis. We used Sample 2 to conduct CFA. This procedure was conducted with a diagonally weighted least squares (DWLS) method, which is specifically designed for use with ordinal data. The first item in each subscale was constrained to a value of one in order to serve as a reference. A higher-order dimension, representing Student Identity was also included in the model because a student identity more completely performing the five functions (higher scores across the five subscales) indicates more developed active self-construction, and thus a more optimal identity. Although the analyses were conducted using unstandardized values, we report standardized factor loadings for clarity. The fit of these models was assessed 
using a set of Goodness-of-fit indices and heuristics: the Chi-square test $\left(\chi^{2}\right)$, and the $\chi^{2} / d f$ to account for sample size; the Tucker Lewis Index (TLI); the Comparative Fit Index (CFI); and the Root-Mean Square Error Approximation (RMSEA). We considered values of CFI and TLI greater than or equal to .95 to be indicative of good model fit (Cangur \& Ercan, 2015; Hu \& Bentler, 1999). Values of RMSEA less than .07 were considered to represent acceptable model fit and values less than .03 excellent fit (Steiger, 2007). $\chi^{2} / d f$ ratios less than 5 were also considered an indication of acceptable model fit (Hooper, Coughlan, \& Mullen, 2008).

Scale unidimensionality. Prior studies of the FIS (e.g. Serafini \& Adams, 2002) have largely modelled this instrument as comprising five related, yet distinct, correlated functions. As a lone exception, Serafini and Maitland (2013) found that a higher-order model had inferior fit to a five-factor correlated model, and thus recommended caution using a total FIS score. Nonetheless, we argue that there are theoretical reasons to think that a total score is meaningful. To assess this as it relates to student identity, we tested a bifactor model in accordance with the method described by Reise, Bonifay and Haviland (2013), which has been used to test other psychological instruments (Brown Yost \& Finney, 2017). Such models account for the variance in scores in terms of a general factor after isolating and then controlling for variance attributed to specific factors.

Considering the work of Reise and colleagues (Reise, 2012; Reise, Moore, \& Haviland, 2010) we made our first assessment of scale unidimensionality by comparing the standardized factor loadings for the general and specific factors of the championed bifactor model. Stronger loadings on the general student factor compared to the specific factors are an indication that it may be appropriate to calculate a total student identity score. Based on the unstandardized factor loadings and error variances obtained from 
the model we then calculated values of Omega $(\omega)$ for: the entire scale $\left(\omega_{\text {Total }}\right.$; reliability of the total FoSIS), and for each subscale ( $\omega_{\text {Factors}}$; reliability of each subscale score); $\omega_{\mathrm{H}}$ (unique reliability of FoSIS after controlling for variance accounted for by specific factors); and $\omega_{\mathrm{s}}$ (unique reliability of subscale after controlling for variance explained by general factor). A value for $\omega_{\mathrm{H}}$ of $>.75$ has been given as a heuristic for accepting the scale has sufficient unidimensionality to calculate and interpret a total scale score (Reise et al., 2013).

Construct Validity. To assess construct validity we calculated Pearson's correlation coefficients between the means scores for each of the FoSIS subscales and a total student identity score, with the five subscales of APSCI. A bootstrapping procedure with 1000 samples was used to estimate $95 \%$ confidence intervals. Correlations were calculated using Samples 1 and 2 combined.

\section{Results}

\section{Exploratory Factor Analysis}

Sample 1 was used for exploratory analyses. As an initial step to determining the factorial structure of the FoSIS we conducted Parallel Analysis. Five components had eigenvalues larger than produced by the random dataset, indicating that five factors should be retained.

An EFA was then conducted to test a five-factor model. Table 1 shows the resulting factor loadings after rotation. The pattern of factor loadings suggested that the model comprised of the following factors: Harmony (items 2, 16, 20, 18 and 25), Objectives (items 1, 13, 7 and 3), Structure (items 9, 5 and 15), Future (items 12, 19 and 4), and Personal Control (items 26, 22, 8 and 10). Loadings ranged between .40 and 94. 


\section{Confirmatory Factor Analysis}

A five-factor model with a higher-order student-identity factor was subjected to CFA using Sample 2. Figure 1 presents the factorial structure and regression weights for this model. This figure shows that with the exception of item $22(.341)$ all items had loadings of above .50 on their respective factors. First-order factors were also shown to load heavily $(.62-.92)$ on the second-order identity factor. The fit statistic for $\chi^{2}$ was 546.79, and this was statistically significant $(p<.001)$, although this was expected with a large sample size. The $\chi^{2} / d f$ ratio, which accounts for sample size, was 3.72, indicating good model fit. Values for CFI (.976) and TLI (.96) were also above the thresholds used to indicate good model fit. RMSEA $(. .10,90 \%$ CI $[.09, .11])$ did not demonstrate good model fit based on a stringent criterion of .07 (Steiger, 2007), although past articles have considered values in this range to represent a fair fit (Maccallum, Browne, \& Sugawara, 1996).

\section{FIGURE 1 ABOUT HERE}

With the exception of Personal Control, the internal consistency of the factors tested in the model (based on Sample 2) was acceptable to good: Harmony $(\alpha=.85)$, Objectives $(\alpha=.81)$, Structure $(\alpha=.78)$, Personal Control $(\alpha=.67)$, Future $(\alpha=.82)$, and Student Identity $(\alpha=.89)$.

\section{Unidimensionality of Student Identity}

The CFA model tested shows good fit with a higher-order identity factor. While this suggests the five subscales measure distinct components of a unidimensional student identity construct, it remains unclear whether the scale is sufficiently unidimensional to calculate a total FoSIS score. We addressed this question by testing a bifactor model, the results of which are presented in Table 2. This model had a better fit 
to the data than the higher-order model, with values for CFI (.98) and TLI (.97) above the threshold of .95. RMSEA (.089) was indicative of an acceptable model fit, as was $\chi^{2} / d f(3.12)$

\section{TABLE 2 ABOUT HERE}

An inspection of this table reveals that fully standardized factor loadings were higher for the general identity factor than for the Harmony (exception item 18) Objectives, and Personal control (exception item 26) specific factors. Conversely, the standardized factor loadings were higher for the Structure and Future (exception item 4) specific factors than the general identity factor. It was therefore unclear from these values whether it is appropriate to calculate a total FoSIS score.

The calculated values for $\omega_{\text {Total }}, \omega_{\mathrm{H}}, \omega_{\mathrm{Factors}}$, and $\omega_{\mathrm{S}}$ are given in Table $3 . \omega_{\mathrm{H}}$ was .79 for our sample, suggesting that $79 \%$ of the variance in FoSIS scores was accounted by the general student identity factor. Considering the value of $\omega_{\text {total }}(.88)$, this indicates that $89 \%(.79 / .88=.92)$ of the reliable variance in FoSIS scores was due to the general factor. This implies that interpretation of a total student identity score is not confused by multidimensionality. Conversely, the calculation of $\omega_{\mathrm{S}}$ for each FoSIS subscale indicated that these subscales explained between $40 \%$ (Personal Control) and 80\% (Harmony) of the variance in scores associated with that specific factor.

\section{TABLE 3 ABOUT HERE}

\section{Association with Stages of Change}

Table 4 presents the Pearson correlation coefficients and 95\% confidence intervals for the relationships between FoSIS subscales and the five stages of change measured by APSCI. The results were consistent with the predictions of the transtheoretical model of change. Firstly, all five subscales were negatively correlated 
with the Precontemplation stage of change, with values ranging from -.12 to -.42.

Secondly, the subscales of the FoSIS were mostly uncorrelated with the Contemplation and Preparation stages of change. The exceptions to this were the Objectives subscale, which was weakly correlated with the Preparation stage $(r=.09)$, and the Personal Control subscale, which was weakly negatively correlated with the Preparation stage ( $r$ $=-.09)$. All five FoSIS subscales were positively correlated with the Action stage, with associations ranging from .08 to .47. Finally, the Harmony and Objectives subscales were weakly, but significantly, correlated with the Maintenance stage of change, although Structure, Future and Personal Control were not significantly correlated.

\section{TABLE 4 ABOUT HERE}

\section{Discussion}

While the Functions of Identity Scale (FIS; Serafini \& Adams, 2002; Serafini \& Maitland, 2013) is a validated measure of the global functions of identity, this scale is limited in the sense that it is inappropriate for assessing functions of identity related to specific contexts. As a result, this instrument is not well aligned with research that indicates a domain-specific consideration of identity may provide a richer account of the complexity of identity development (Goossens, 2001; Marcia, 1966; Pastorino et al., 1997). Furthermore, being able to measure and understand functions of identity in the context of being a student is critical because student identity is linked to behavioral change and associated with academic performance. We therefore developed a measure of the functions of identity as they relate to being a student (the FoSIS) and conducted some initial tests of its factorial structure and psychometric properties.

The results of a series of different factor analyses strongly support the existence of a five-factor scale structure corresponding to the five functions of identity proposed 
by Adams and Marshall (1996). Parallel analysis revealed five factors, and subsequent exploratory analysis showed that the items loaded on their pre-assigned factors. Having established an internal structure of the FoSIS, we used a second subsample to test whether data could be modeled in terms of a second-order structure. We tested this particular model because more complete functioning can be considered to represent more active self-construction and, ergo, optimal identity development (Adams \& Marshall, 1996). This second-order model was found to have good fit to our data. We then tested a bifactor model and calculated bifactor statistical indexes, a novel approach for measures of the functions of identity. These analyses indicated that it is acceptable to model the functions of student identity in terms of one general factor and five specific factors (corresponding to the five functions), and that the general student identity factor alone explains a sufficiently large proportion of the variance in FoSIS scores to be considered a unidimensional construct. In other words, this analysis demonstrates that student identity, as measured by the FoSIS, is sufficiently unidimensional for researchers and clinicians to accurately interpret a total FoSIS score.

In terms of the other psychometric properties of this new instrument, all but one subscale (Personal Control) revealed at least acceptable internal consistency, providing reasonable support for the structural validity of the measure. Curiously, a smaller alpha has been identified consistently for the Personal Control function in past studies (Crocetti et al., 2010; Serafini \& Adams, 2002) and indeed, the problems with this subscale were explicitly addressed by Serafini and Maitland (2013). It is possible that the lower reliability of this subscale reflects the nature of the items, specifically designed for this instrument, which might be remedied in the future by some revision. However, given the repeated pattern of lower reliability across past studies it is possible that all current conceptualizations of identity functions do not precisely capture this 
construct. That said, more recent articles have shown a shift in conceptual focus in this subscale from locus of control to personal agency and self-regulation improved scale reliability (e.g. "I am self-directed when I set my goals", Serafini \& Maitland, 2013), and it is possible that strengthening this emphasis in the FoSIS will improve its reliability.

We also found evidence of convergent validity by correlating FoSIS subscale and total scores with subscale scores from the Academic Performance Stages of Change. Our rationale for this analysis was that the functions of identity are theoretically and empirically linked to behavior change (Webb \& Sheeran, 2006). It therefore logically followed that low FoSIS scores, indicating a passive identity development, would be associated with a lack of behavioral change (the Preparation Stage of change), and that high FoSIS scores, indicating active self-construction, would be positively associated with high levels of behavioral change (the Action stage of change). Our results were consistent with these theoretical predictions, thus providing support for the conceptualization of student identity as measured by the items of the FoSIS.

One issue at the conceptual level concerns whether the identity functions framework (Adams \& Marshall, 1996), which was formulated in terms of global identity, should be applied across domains. Are the functions that apply to global identity the same as those which apply to more specific social contexts? If not, it may be the case that the FoSIS is an inaccurate measure of the functions of student identity. Nonetheless, empirical evidence does show there is little convergence in identity status across domains (Goossens, 2001; Pastorino et al., 1997), and because identity status is not mutually exclusive from the functions of identity, we argue that the development of measures of context-specific identity functions is a relevant and worthwhile endeavor. 
Our results provide some initial empirical support for the five functions of identity in the context of being a student, therefore demonstrating the robustness of the functions of identity framework across domains.

\section{Limitations and future research}

Although this study provides evidence that the FoSIS has acceptable psychometric properties, it also has some limitations. Several factors, for example, limit the generalizability of our findings. Our sample, which was not recruited using a fully randomized procedure, comprised Portuguese high-school students. What this suggests is that it is difficult to generalize the applicability of the FoSIS to different student samples within Portugal (e.g. younger adolescents or university students) or to student samples from countries and cultures different to Portugal. This latter issue may be particularly important to address since researchers have highlighted that cultural differences (e.g. collectivist vs. individualist values) have implications for identity (Lo, Helwig, Chen, Ohashi, \& Cheng, 2011). That said, Erikson's (1968) formulation of identity implied that identity development is a universal phenomenon, and this is reasonably supported by the fact that the Functions of Identity Scale (FIS) has been validated across three different cultural groups, including both collectivist and individualist samples (Crocetti et al., 2010; Demir, 2011; Serafini \& Maitland, 2013). More studies are clearly necessary to develop and validate versions of the FoSIS in languages other than Portuguese, and to assess whether such scales show measurement invariance across cultures.

Although this article offers some assessment of the psychometric properties of the FoSIS, presenting assessments of internal consistency and convergent validity, the study is preliminary in nature, and more studies are required to fully understand whether the FoSIS is a valid and reliable measure of student identity. This study was cross- 
sectional, rather than longitudinal, and we were therefore unable to assess the test-retest reliability of the FoSIS. Future studies should also consider conducting tests of measurement invariance. Although initial research into identity development failed to identify gender differences (Kroger, 1997) and often adopted a gender-free approach, more current studies have shown gender differences (Cramer, 2000; Lewis, 2003). Prior to testing whether males and females differ in their responses to the FoSIS, it is prerequisite that the construct is determined to be equivalent for both groups (Cheung \& Rensvold, 2002). The Functions of Identity Scale (FIS), which measures more generalized functions of the identity construct than the FoSIS, has been shown to have measurement invariance across gender and age (Crocetti, Sica, Schwartz, Serafini, \& Meeus, 2010), but it nonetheless remains important to establish this psychometric property in the FoSIS. Besides the two variables already discussed, culture and gender, future work should also eventually examine the impact of other student-level (e.g. socioeconomic status and student academic ability) and school/college-level factors (e.g. support for learning) on the functions of student identity. Longitudinal studies of large samples nested in multiple schools and adopting multilevel methods would be useful in this area as a means to investigate the role of these variables, and the interactions between them, in predicting student identity and its influence on academic outcomes.

\section{Practical applications and future research}

Although this preliminary study has limitations, it presents some initial findings that suggest the FoSIS is a promising tool for assessing the functions of student identity in Portuguese adolescents. With further development and validation, we anticipate that the FoSIS may have some important practical applications. For example, our findings can be used help inform those interested in assessing identity by highlighting that; a) student 
identity can be conceptualized in terms of the five functions proposed by Adams and Marshall (1996); and b) the degree to which these functions are present can be used as an indication of an individual's active self-construction in the context of school. For example, research needs to describe the associations between the functions of student identity and personality, as they contribute to a better understanding of adolescents development, including academic trajectories and wellbeing (Moreira Oliveira, Cloninger, Azevedo, Sousa, Castro, \& Cloninger, 2013; Moreira, Cloninger, Dinis, Sa, Oliveira, Dias, \& Oliveira, 2014). This detailed understanding of student identity may then be relevant for teachers, educational psychologists and school policy makers interested in maximizing student academic performance and engagement with school. This understanding, coupled with access to the FoSIS (which has a small number of items and therefore will be easy to administer) may be valuable for identifying students who may be at risk of disengagement, school dropout and poor academic performance, and helping to design targeted interventions for these individuals. Such interventions, for example, might incorporate helping students to define their student goals (Objective function), or alternatively to understand their characteristics and qualities as students (Structure function).

\section{Summary}

Our primary objective was to construct a measure of student identity adopting a functions of identity perspective (Adams \& Marshall, 1996), and to conduct some preliminary tests of this scale's factorial structure, multidimensionality, and convergent validity. Our proposed instrument, the Functions of Student Role Identity Scale, revealed a factorial structure consistent with the five functions of identity. Our test of multidimensionality indicates that those choosing to use this scale should be wary of calculating and interpreting a global student identity score. Finally, the five subscales 
showed tentative internal consistency, although they correlated in line with theoretical expectations with a measure of behavioral change.

\section{References}

Abraham, K. G. (1983). The Relation between Identity Status and Locus of Control among Rural High School Students. The Journal of Early Adolescence, 3(3), 257264. https://doi.org/10.1177/0272431683033008

Adams, G. R., Berzonsky, M. D., \& Keating, L. (2006). Psychosocial resources in firstyear university students: The role of identity processes and social relationships. Journal of Youth and Adolescence, 35(1), 81-91. https://doi.org/10.1007/s10964005-9019-0

Adams, G. R., \& Ethier, J. L. (1999). The objective measure of ego identity status: A manual on theory and test construction. Department of Family Relations and Applied Nutrition, University of Guelph, Guelph, Ontario, Canada.

Ajzen, I. (1985). From intentions to actions: A theory of planned behavior. In J. Kuhl \& J. Beckmann (Eds.), Action-control: From Cognition to Behaviour (pp. 11-39). Heidelberg: Springer.

Ajzen, I. (1987). Attitudes, traits, and actions: Dispositional predictions of behavior in personality and social psychology. In L. Berkowitz (Ed.), Advances in Experimental Social Psychology (pp. 1-64). New York, NY: Academic Press.

Berzonsky, M. D. (1989). Identity style: Conceptualization and measurement. Journal of Adolescent Research, 4, 268-282. https://doi.org/10.2753/MIS07421222310104 
Berzonsky, M. D. (2004). Identity style, parental authority, and identity commitment. Journal of Youth and Adolescence, 33(3), 213-220. https://doi.org/10.1023/B:JOYO.0000025320.89778.29

Biddle, B. J., Bank, B. J., \& Slavings, R. L. (1987). Norms, Preferences, Identities and Retention Decisions. Social Psychology Quarterly, 50(4), 322. https://doi.org/10.2307/2786817

Blustein, D. L., \& Palladino, D. E. (1991). Self and identity in late adoelscence: A theoretical and empirical integration. Journal of Adolescence, 6(4), 437-453. https://doi.org/0803973233

Brown Yost, A., \& Finney, S. J. (2017). Assessing the Unidimensionality of Trait Reactance Using a Multifaceted Model Assessment Approach. Journal of Personality Assessment, 100(2), 186-196.

https://doi.org/10.1080/00223891.2017.1280044

Cangur, S., \& Ercan, I. (2015). Comparison of Model Fit Indices Used in Structural Equation Modeling Under Multivariate Normality. Journal of Modern Applied Statistical Methods, 14(1), 152-167.

Cheung, G. W., \& Rensvold, R. B. (2002). Evaluating Goodness-of-Fit Indexes for Testing Measurement Invariance. Structural Equation Modeling, 9(2), 233-255. https://doi.org/10.1207/S15328007SEM0902_5

Chorba, K., Was, C. A., \& Isaacson, R. M. (2012). Individual differences in academic identity and self-handicapping in undergraduate college students. Individual Differences Research, 10(2), 60-68.

Cramer, P. (2000). Development of Identity: Gender Makes a Difference. Journal of 
Research in Personality, 34(1), 42-72. https://doi.org/10.1006/jrpe.1999.2270

Crocetti, E., Sica, L. S., Schwartz, S. J., Serafini, T., \& Meeus, W. (2010). The functions of identity scale: Validation in Italian late adolescents and emerging adults. TPM - Testing, Psychometrics, Methodology in Applied Psychology, 17(2), $55-71$.

Crocetti, E., Sica, L. S., Schwartz, S. J., Serafini, T., \& Meeus, W. (2013). Identity styles, dimensions, statuses, and functions: Making connections among identity conceptualizations. Revue Europeenne de Psychologie Appliquee, 63(1), 1-13. https://doi.org/10.1016/j.erap.2012.09.001

Deaux, K. (1993). Reconstructing Social Identity. Personality and Social Psychology Bulletin, 19(1), 4-12. https://doi.org/10.1177/0146167293191001

Erikson, E. H. (1968). Identity: Youth and crisis. New York, NY: Norton.

Goossens, L. (2001). Global versus domain-specific statuses in identity research: A comparison of two self-report measures. Journal of Adolescence, 24(6), 681-699. https://doi.org/10.1006/jado.2001.0438

Grotevant, H. D. (1993). The integrative nature of identity: Bringing the soloists to sing in the choir. In J. Kroger (Ed.), Discussion on ego identity (pp. 121-146). Hillsdale, NJ: Lawrence Erlbaum Associates.

Hejazi, E., Lavansani, M. G., Amani, H., \& Was, C. A. (2012). Academic identity status, goal orientation, and academic achievement among high school students. Journal of Research in Education, 22, 291-320.

Hooper, D., Coughlan, J., \& Mullen, M. R. (2008). " Structural Equation Modelling: Guidelines for Determining Model Fit Structural Equation Modelling: Guidelines 
for Determining Model Fit. The Electronic Journal of Business Research Methods, 6(1), 53-60. https://doi.org/10.1037/1082-989X.12.1.58

Howard, J. A. (2000). Social Psychology of Identities. Annual Review of Sociology, 26(1), 367-393. https://doi.org/10.1146/annurev.soc.26.1.367

Hu, L., \& Bentler, P. M. (1999). Cutoff criteria for fit indexes in covariance structure analysis: Conventional criteria versus new alternatives. Structural Equation Modeling: A Multidisciplinary Journal, 6(1), 1-55.

Hutcheson, G., \& Sofroniou, N. (1999). The multivariate social scientist: introductory statistics using generalized linear models. Thousand Oaks, CA: Sage Publications.

Ireri, A. M., Wawire, C. K., Mugambi, D. K., \& Mwangi, C. N. (2015). Academic Identity Status Measure: Psychometric Properties when Used among Secondary School Students in Kenya. International Journal of School and Cognitive Psychology, 2(4). https://doi.org/10.4172/2469-9837.1000150

Komarraju, M., \& Dial, C. (2014). Academic identity, self-efficacy, and self-esteem predict self-determined motivation and goals. Learning and Individual Differences, 32, 1-8. https://doi.org/10.1016/j.lindif.2014.02.004

Kroger, J. (1997). Gender and Identity The Intersection of Structure, Content, and Contex. Sex Roles, 36, 747-770. https://doi.org/10.1023/A:1025627206676

Lewis, H. (2003). Differences in Ego Identity Among College Students Across Age, Ethnicity, and Gender. Identity, 3(2), 159-189. https://doi.org/10.1207/S1532706XID030205

Lillevoll, K. R., Kroger, J., \& Martinussen, M. (2013). Identity Status and Locus of Control: A Meta-Analysis. Identity, 13(3), 253-265. 
https://doi.org/10.1080/15283488.2013.799471

Lo, C., Helwig, C. C., Chen, S. X., Ohashi, M. M., \& Cheng, C. M. (2011). A needsbased perspective on cultural differences in identity formation. Identity, 11(3), 211-230. https://doi.org/10.1080/15283488.2011.594782

Maccallum, R. C., Browne, M. W., \& Sugawara, H. M. (1996). Power analysis and determination of sample size for covariance structure modeling of fit involving a particular measure of model. Psychological Methods, 13(2), 130-149. https://doi.org/10.1037/1082-989X.1.2.130

Marcia, J. E. (1966). Development and validation of ego-identity status. Social Psychology, 3(5), 551-558.

Marcia, J. E. (1980). Identity in Adolescence. In J. Adelson (Ed.), Handbook of Adolescent Psychology. New York, NY: Wiley \& Sons.

Moreira, P. A. S., \& Cardosa, N. M. (2010). Escala de Identidade de Papel de Estudante. Porto.

Moreira, P. A. S., Dias, P., Vaz, F. M., \& Vaz, J. M. (2013). Predictors of academic performance and school engagement - Integrating persistence, motivation. Learning and Individual Differences, 24, 117-125.

Moreira, P. A. S., Moreira, F., Cunha, D., \& Inman, R. A. (2018). The Academic Performance Stages of Change Inventory (APSCI): An application of the Transtheoretical Model to academic performance. Manuscipt Submitted for Publication.

Noftle, E. E., \& Robins, R. W. (2007). Personality Predictors of Academic Outcomes: Big Five Correlates of GPA and SAT Scores. Journal of Personality and Social 
Psychology, 93(1), 116-130. https://doi.org/10.1037/0022-3514.93.1.116

Oyserman, D. (2007). Social identity and self-regulation. In A. W. Kruglanski \& E. T. Higgins (Eds.), Handbook of Social Psychology (pp. 432-453). New York, NY: Guilford Press.

Oyserman, D. (2009). Identity-based motivation: Implications for action-readiness, procedural-readiness, and consumer behavior. Journal of Consumer Psychology, 19(3), 250-260. https://doi.org/10.1016/j.jcps.2009.05.008

Oyserman, D., Lewis, N. A., Yan, V. X., Fisher, O., O’Donnell, S. C., \& Horowitz, E. (2017). An Identity-Based Motivation Framework for Self-Regulation. Psychological Inquiry, 28(2-3), 139-147. https://doi.org/10.1080/1047840X.2017.1337406

Pastorino, E., Dunham, R. M., Kidwell, J., Bacho, R., \& Lamborn, S. D. (1997). Domain-specific gender comparisons in identity development among college youth: Ideology and relationships. Adolescence, 32(127), 559-578.

Poropat, A. E. (2009). A Meta-Analysis of the Five-Factor Model of Personality and Academic Performance. Psychological Bulletin, 135(2), 322-338. https://doi.org/10.1037/a0014996

Reise, S. P. (2012). The Rediscovery of Bifactor Measurement Models. Multivariate Behavioral Research, 47(5), 667-696. https://doi.org/10.1080/00273171.2012.715555

Reise, S. P., Bonifay, W. E., \& Haviland, M. G. (2013). Scoring and modeling psychological measures in the presence of multidimensionality. Journal of Personality Assessment, 95(2), 129-140. 
https://doi.org/10.1080/00223891.2012.725437

Reise, S. P., Moore, T. M., \& Haviland, M. G. (2010). Bifactor models and rotations: Exploring the extent to which multidimensional data yield univocal scale scores. Journal of Personality Assessment, 92(6), 544-559.

https://doi.org/10.1080/00223891.2010.496477.Bifactor

Roeser, R. W., Galloway, M., Casey-Cannon, S., Watson, C., Keller, L., \& Tan, E. (2008). Identity Representations in Patterns of School Achievement and well-being among early adolescent girls: Variable-and Person-Centered Approaches. Journal of Early Adolescent, 28, 115-152.

Rogow, A. M., Marcia, J. E., \& Slugoski, B. R. (1983). The relative importance of identity status interview components. Journal of Youth and Adolescence, 12(5), 387-400. https://doi.org/10.1016/S0140-1971(86)80040-9

Ryeng, M. S., Kroger, J., \& Martinussen, M. (2013). Identity Status and Self-Esteem: A Meta-Analysis. Identity, 13(3), 201-213. https://doi.org/10.1080/15283488.2013.799431

Schwartz, S. J. (2001). The Evolution of Eriksonian and, Neo-Eriksonian Identity Theory and Research: A Review and Integration. Identity, 1(1), 7-58. https://doi.org/10.1207/S1532706XSCHWARTZ

Schwartz, S. J., Beyers, W., Luyckx, K., Soenens, B., Zamboanga, B. L., Forthun, L. F., ... Waterman, A. S. (2011). Examining the light and dark sides of emerging Adults' identity: A study of identity status differences in positive and negative psychosocial functioning. Journal of Youth and Adolescence, 40(7), 839-859. https://doi.org/10.1007/s10964-010-9606-6 
Serafini, T. E., \& Adams, G. R. (2002). Functions of Identity: Scale Construction and Validation. Identity, 2(4), 287-301. https://doi.org/10.1207/S1532706XID0204

Serafini, T. E., \& Maitland, S. B. (2013). Validating the Functions of Identity Scale: Addressing Methodological and Conceptual Matters. Psychological Reports, 112(1), 160-183. https://doi.org/10.2466/03.07.20.PR0.112.1.160-183

Steiger, J. H. (2007). Understanding the limitations of global fit assessment in structural equation modeling. Personality and Individual Differences, 42(5), 893-898. https://doi.org/10.1016/j.paid.2006.09.017

Terry, D. J., Hogg, M. ., \& White, K. M. (1999). The theory of planned behaviour: selfidentity, social identity and group norms. British Journal of Social Psychology, 38, 225-244. https://doi.org/10.1348/014466699164149

Was, C. A., Al-Harthy, I., Stack-Oden, M., \& Isaacson, R. M. (2009). Academic identity status and the relationship to achievement goal orientation. Electronic Journal of Research in Education Psychology, 7(2), 627-652.

Was, C. A., \& Isaacson, R. M. (2008). The development of a measure of academic identity status. Journal of Research in Education, 18, 94-105.

Webb, T. L., \& Sheeran, P. (2006). Does changing behavioral intentions engender behavior change? A meta-analysis of the experimental evidence. Psychological Bulletin, 132(2), 249-268. https://doi.org/10.1037/0033-2909.132.2.249 
Table 1

Summary of exploratory factor analysis

\begin{tabular}{|c|c|c|c|c|c|c|}
\hline Item & $\operatorname{Text}^{\mathrm{a}}$ & Harmony & Objectives & Structure & Future & $\begin{array}{r}\text { Personal } \\
\text { Control }\end{array}$ \\
\hline 20 & I like being a student & .80 & .00 & .01 & .05 & -.01 \\
\hline 18 & If I could I would not be a student (reversed) & .72 & -.03 & -.07 & -.01 & .13 \\
\hline 2 & I feel good about being a student & .70 & .16 & .10 & -.01 & -.04 \\
\hline 16 & $\begin{array}{l}\text { Among the many things that young people } \\
\text { can be (e.g., work), being a student is one of } \\
\text { the things that I identify myself with }\end{array}$ & .68 & -.04 & .08 & .02 & -.05 \\
\hline 25 & I'm a student because I want to be & .46 & -.01 & -.09 & -.04 & .39 \\
\hline 13 & $\begin{array}{l}\text { When I make a decision, I think about the } \\
\text { implications this will have on my student life }\end{array}$ & .00 & .81 & .06 & .00 & .01 \\
\hline 7 & I avoid things that undermine my student life & -.05 & .79 & -.05 & -.03 & .01 \\
\hline 1 & $\begin{array}{l}\text { In general, before doing anything, I think if } \\
\text { this will harm my student life }\end{array}$ & .08 & .69 & .02 & .02 & -.01 \\
\hline 3 & $\begin{array}{l}\text { I strive to achieve the goals I have as a } \\
\text { student }\end{array}$ & .20 & .44 & -.08 & .17 & .11 \\
\hline 9 & $\begin{array}{l}\text { I know what my characteristics are as a } \\
\text { student }\end{array}$ & .02 & -.04 & .94 & -.04 & .03 \\
\hline 5 & $\begin{array}{l}\text { I know what my main qualities are as a } \\
\text { student }\end{array}$ & .08 & .09 & .71 & .08 & -.04 \\
\hline 15 & I am aware of the type of student I am & -.12 & .11 & .55 & .13 & .15 \\
\hline 19 & $\begin{array}{l}\text { I have a clear idea of what my future will be } \\
\text { as a student }\end{array}$ & -.04 & .00 & -.02 & .86 & .02 \\
\hline 12 & $\begin{array}{l}\text { I am easily able to anticipate how I will be as } \\
\text { a student in the near future }\end{array}$ & .03 & -.09 & .08 & .72 & -.05 \\
\hline 4 & $\begin{array}{l}\text { I have a clear idea of how I will be a student } \\
\text { in the near future }\end{array}$ & .11 & .15 & -.05 & .57 & .05 \\
\hline 26 & $\begin{array}{l}\text { It is I who make the main decisions related to } \\
\text { my studies }\end{array}$ & .03 & .00 & .03 & .02 & .70 \\
\hline 10 & $\begin{array}{l}\text { What I do as a student results from my } \\
\text { decisions }\end{array}$ & -.02 & .05 & .11 & .01 & .54 \\
\hline 22 & $\begin{array}{l}\text { I'd rather have other people tell me what I } \\
\text { have to do as a student than to decide what to } \\
\text { do (reversed) }\end{array}$ & .02 & .04 & .01 & .01 & .47 \\
\hline 8 & $\begin{array}{l}\text { I like to participate and have a say in } \\
\text { decisions related to my student life }\end{array}$ & .03 & .07 & .24 & .05 & .40 \\
\hline & SS loadings & 2.64 & 2.20 & 1.96 & 1.77 & 1.67 \\
\hline & $\%$ of total variance explained by factor & $52.8 \%$ & $55.0 \%$ & $65.3 \%$ & $59.0 \%$ & $41.8 \%$ \\
\hline
\end{tabular}

Notes. ${ }^{a}$ Items translated from Portuguese; SS loadings $=$ Sums of squared loadings 
Table 2 .

Unstandardized (and fully standardized) factor loadings and error variance for the bifactor model.

\begin{tabular}{|c|c|c|c|c|c|c|c|}
\hline Item & $\begin{array}{l}\text { Student } \\
\text { Identity }\end{array}$ & Harmony & Objectives & Structure & Future & $\begin{array}{c}\text { Personal } \\
\text { Control }\end{array}$ & $\begin{array}{c}\text { Error } \\
\text { Variance }\end{array}$ \\
\hline 20 & $1.00(.59)$ & $1.00(.65)$ & & & & & .23 \\
\hline 18 & $0.47(.28)$ & $1.22(.80)$ & & & & & .29 \\
\hline 2 & $0.88(.52)$ & $1.00(.65)$ & & & & & .31 \\
\hline 16 & $0.63(.37)$ & $0.84(.55)$ & & & & & .56 \\
\hline 25 & $0.99(.58)$ & $0.70(.45)$ & & & & & .46 \\
\hline 13 & $1.13(.67)$ & & $1.00(.60)$ & & & & .20 \\
\hline 7 & $1.03(.60)$ & & $0.80(.48)$ & & & & .41 \\
\hline 1 & $1.03(.61)$ & & $0.84(.51)$ & & & & .38 \\
\hline 3 & $1.36(.80)$ & & $0.25(.15)$ & & & & .34 \\
\hline 9 & $0.88(.52)$ & & & $1.00(.67)$ & & & .28 \\
\hline 5 & $0.81(.48)$ & & & $1.01(.68)$ & & & .31 \\
\hline 15 & $0.99(.58)$ & & & $0.95(.64)$ & & & .25 \\
\hline 19 & $0.93(.55)$ & & & & $1.00(.62)$ & & .31 \\
\hline 12 & $0.72(.42)$ & & & & $0.97(.61)$ & & .46 \\
\hline 4 & $1.05(.62)$ & & & & $0.75(.47)$ & & .40 \\
\hline 26 & $1.07(.63)$ & & & & & $1.00(.48)$ & .38 \\
\hline 10 & $0.82(.48)$ & & & & & $0.39(.19)$ & .73 \\
\hline 22 & $0.50(.29)$ & & & & & $0.81(.39)$ & .76 \\
\hline 8 & $1.06(.62)$ & & & & & $-0.03(-.01)$ & .62 \\
\hline
\end{tabular}


Table 3.

Omega values for the general and specific factors as well as Omega ${ }_{H}$ and Omegas

\begin{tabular}{lcccc} 
& $\omega_{\text {Total }}$ & $\omega_{\mathrm{H}}$ & $\omega_{\text {Factor }}$ & $\omega_{\mathrm{S}}$ \\
\hline Student Identity & .88 & .79 & .87 & .70 \\
Harmony & & & .81 & .43 \\
Objectives & & .87 & .62 \\
Structure & & .78 & .48 \\
Future & & & .56 & .22 \\
Personal Control & & & & \\
\hline
\end{tabular}


Table 4

Pearson correlations between FoSIS subscales (functions of student identity) and the APSCI stages of change.

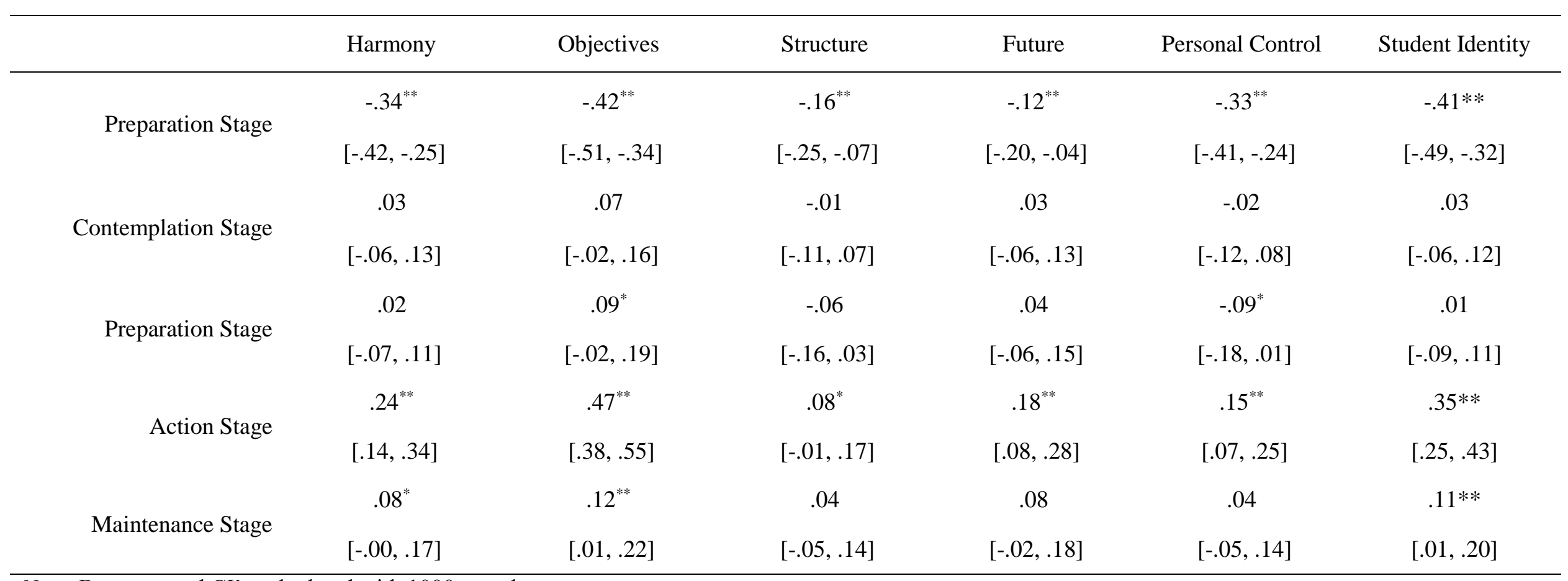

Note. Bootstrapped CI's calculated with 1000 samples. 


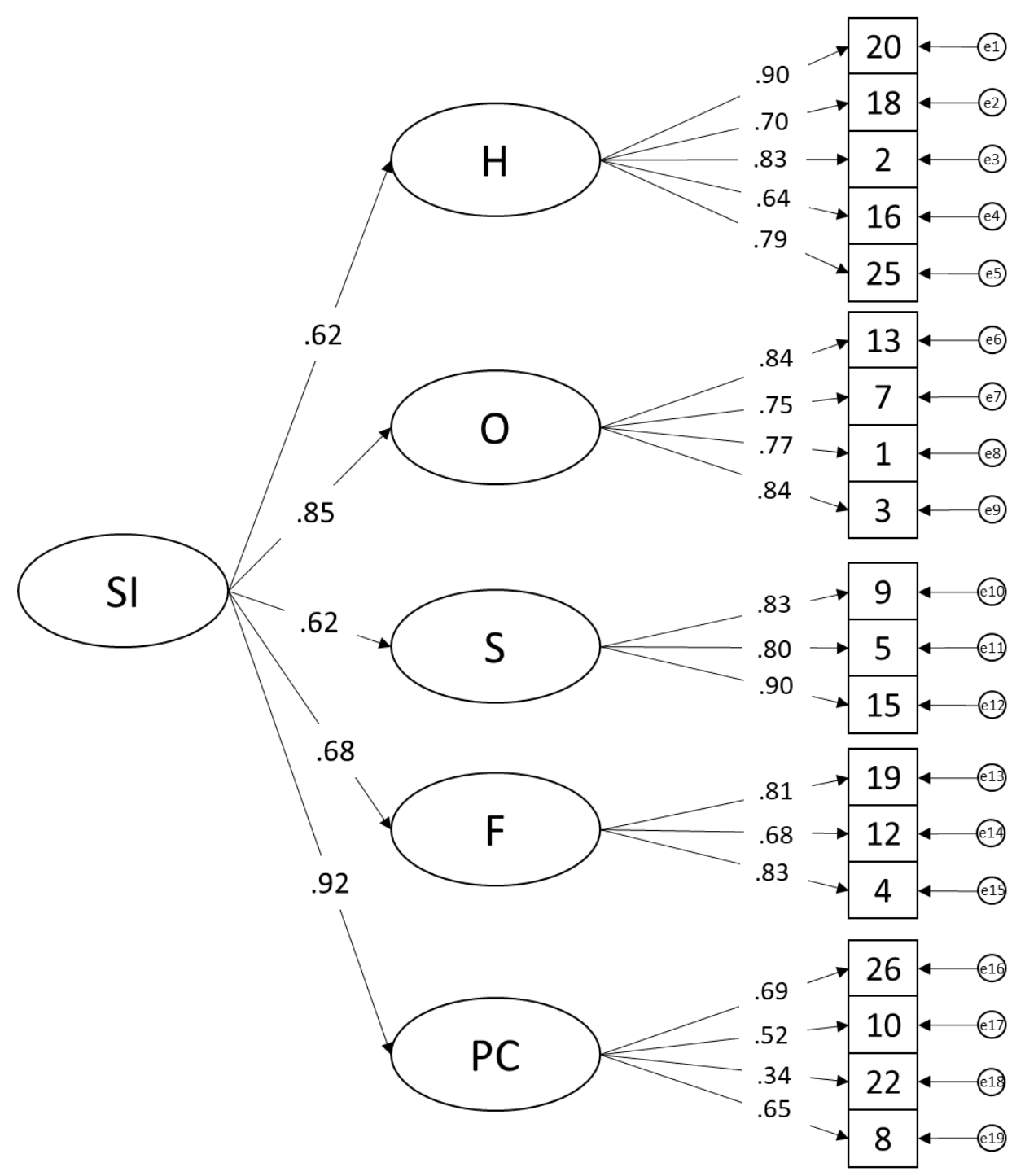

Figure 1. Full structural model and standardized factor loadings for the higher-order model used to evaluate the Functions of Student Identity Scale. See Table 1 for items. $\mathrm{SI}=$ Student Identity $; \mathrm{H}=$ Harmony $; \mathrm{O}=$ Objectives $; \mathrm{S}=$ Structure $; \mathrm{F}=$ Future $; \mathrm{PC}=$ Personal Control. 